\title{
Process optimization for production of biodiesel from croton oil using two-stage process
}

\author{
W. O. Osawa ${ }^{1}$, J. M. Onyari ${ }^{1}$, P. K. Sahoo ${ }^{3}$, F. J. Mulaa ${ }^{2}$, \\ ${ }^{I}$ Department of Chemistry, College of Biological and Physical Sciences, University of Nairobi, P.O. Box 30197 - \\ 00100, Nairobi, Kenya. \\ ${ }^{2}$ Department of Biochemistry, College of Health Sciences, University of Nairobi, P.O. Box 30197 - 00100, \\ Nairobi, Kenya \\ ${ }^{3}$ Department of Mechanical Engineering, University of Petroleum \& Energy Studies, Dehradun \\ 248007 (Uttarakhand), India
}

\begin{abstract}
Croton oil was extracted from dry seeds by a mechanical pressing machine then filtered to remove solid impurities. Biodiesel was prepared from the oil through a two-stage process in a biodiesel reactor. The optimum reaction conditions were determined by varying parameters such as temperature, oil:methanol ratio and amount of catalysts used. The optimum conditions established in this study were temperatures of $50^{\circ} \mathrm{C}$ and $60^{\circ} \mathrm{C}$ for esterification and transesterification respectively, methanol:oil ratio of 3:1 and 6:1 for esterification and transesterification respectively and a base catalyst mass of $1 \%(w / w)$ of the oil for transesterification. Esterification was done for two hours while transesterification was done for one hour. A maximum yield of $88 \%$ biodiesel which had an acid value of $0.336 \mathrm{mg} \mathrm{KOH} / \mathrm{g}$, a density of $0.8858 \mathrm{~g} / \mathrm{cm}^{3}$ and viscosity of $4.51 \mathrm{cs}$ at $40^{\circ} \mathrm{C}$ was obtained. The flash point of the biodiesel was greater than $200^{\circ} \mathrm{C}$ which made it safer to store and transport as compared to diesel which had a flash point of $65^{\circ} \mathrm{C}$. Both the cloud and pour points of the biodiesel were lower than that of petro-diesel, implying that its blends were more suitable for lower temperature operations. All properties of the biodiesel that were tested satisfied the recommended American Society for Testing and Materials (ASTM) values.
\end{abstract}

Keywords: Croton oil, Biodiesel, Optimization, Two-stage process, High FFA

\section{Introduction}

The increasing fuel demand and pollution caused by automobile and industrial emission have made biodiesel to be considered as a major substitute for petro-diesel. Since petroleum fuel sources are finite, the search for alternative fuel is currently going on all over the world. The rising cost of petroleum fuels, depletion of reserves and strict world protocols on exhaust emissions have also necessitated the need for replacement of petroleum fuels with less polluting, readily available and renewable non-edible sources of fuels for automobile and industrial engines (Sahoo and Das, 2009). The high efficiency and cost effectiveness of diesel engines have made them to be widely used in most internal combustion engines. Their efficiency is due to high compression ratio that creates heat and cause spontaneous ignition of fuel (Robert, 2001).

The incessant recognition of diminishing petroleum fuel reserves and possibility of using readily available low cost non-edible plant and waste-oils as sources of environment-friendly renewable substitutes have created a lot of interest in biodiesel research (Agarwal and Das, 2001). Biodiesel consists of alkyl esters of fatty acids and can be easily prepared from animal fats, plant or vegetable seed and restaurant waste oils (Canakci and Van Gerpen, 2001). Base catalyzed transesterification reactions employing sodium hydroxide $(\mathrm{NaOH})$ or potassium hydroxide $(\mathrm{KOH})$ which are extensively used in commercial production of biodiesel are pretty fast but are sensitive to presence of water and free fatty acids (Van Gerpen et al., 2004). The most commonly employed biodiesel, fatty acid methyl esters (FAME) are normally produced by transesterification of oils or fats with methanol in the presence of an alkaline catalyst (Upathyay and Sharma, 2013).

Transesterification is the transformation of long and branched triglycerides (TGs) into shorter and straight chain molecules whose size and physical properties are similar to those of petro-diesel (Sinha et al., 2008). Even though each mole of TG, requires three moles of alcohol for complete reaction, a higher molar ratio of alcohol is normally used in order to shift equilibrium of the reversible reaction and result in improved biodiesel yield. The molar ratio employed depends on the oil feedstock, catalyst used, temperature and reaction time (Sharma et al., 2008). Excessive amount of alcohol causes increased emulsification and makes recovery of glycerol difficult. The ideal alcohol:oil ratio should therefore be established experimentally for each oil feedstock (Christie, 1989). Transesterification can be carried out using different catalysts such as alkali, acid or lipases which promotes hydrolysis of triglycerides to fatty acids and glycerol. The biodiesel is then purified through a separation step that involves washing with warm water (Taher et al., 2011). The general chemical equation for transesterification can be represented as shown in equation 1: 


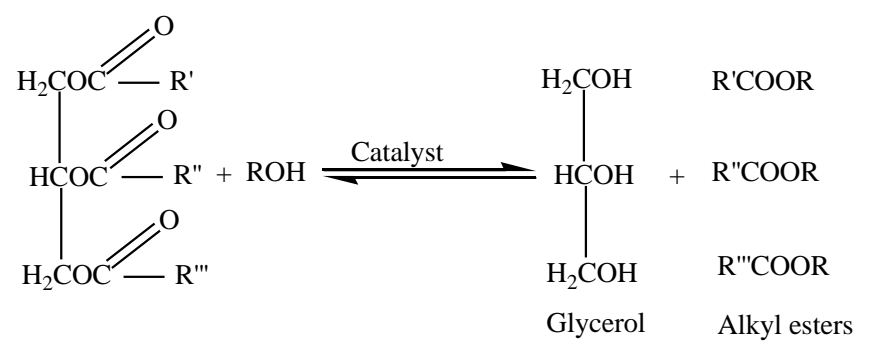

(Equation 1)

In alkali-catalyzed transesterification, the alkali is dissolved in alcohol and the resulting solution mixed with oil feedstock in a biodiesel reactor with vigorous stirring for $1-2$ hours at about 335K (Dermibas, 2009). Although acid catalysts gives very high yields of biodiesel, the reactions are relatively slow. Thus, despite their sensitivity to water and free fatty acid content, base catalyzed reactions still dominate large scale production of biodiesel (Van Gerpen et al., 2004). Canakci and Van Gerpen, (2001) developed a two-stage process for preparing biodiesel from oil feedstocks with high free fatty acids (FFAs) which involves reduction of FFAs through acid-catalyzed esterification followed by base catalyzed transesterification.

Sahoo and Das, (2009) observed that production of fuel grade biodiesel from feedstocks with high free fatty acid content such as Polanga oil using direct alkali-catalyzed transesterification resulted in very low yields due to soap formation. They reported that two-step process for Jatropha and Karanja; and triple step process for Polanga oils greatly improved the yield of fuel grade biodiesel. Canakci and Van Gerpen, (2001) reported that acid-catalyzed pre-treatment reactions reduced the acid values of oils containing high free fatty acids to less than $2 \mathrm{mg} \mathrm{KOH} / \mathrm{g}$. They noted that increasing the amount of acid catalyst was very effective in decreasing the acid values of the oil feedstocks.

Croton megalocarpus Hutch. belongs to the family Euphorbiaceae. The plant grows commonly in tropical East Africa at altitude ranges of 4,000 to 6,700 feet and is widely used as a shade tree in coffee plantations and within homes. It may reach a height of 120 feet, with a clear cylindrical pole measuring between 40 to 60 feet in length and trunk diameters of 2 to 4 feet (Bolza and Keating, 1972). The plant starts bearing nuts at 3 years and matures at about 11 years. Croton oil can be obtained by pressing the dry nuts to obtain straight vegetable oil (SVO) which can be used in preparation of biodiesel. The plant grows readily in many parts of Kenya and is widely distributed in many forests, farms and homes.

Despite the availability of large amounts of non-edible plant and waste oils such as croton seed, restaurant waste and Nile perch viscera oil that can be used as sources of biodiesel feedstocks in many developing countries such as Kenya, no considerable effort has been made to prepare and use biodiesel on large scale. Some of the readily available non-edible plant and waste oil feedstocks possess high FFA content hence making the usually employed alkali-catalyzed transesterification reactions unsuitable. It is therefore important to establish optimum conditions for conversion of specific non-edible oil feedstock with high FFA using the twostage process that can be employed in large scale production of biodiesel. In this study, optimum conditions for conversion of croton oil into biodiesel using the two-stage process were investigated. The properties of croton biodiesel were also tested and compared with recommended ASTM values and those of petro-diesel.

\subsection{Materials}

\section{Materials and Methods}

Croton megalocarpus fruits were collected at Chiromo Campus of University of Nairobi and around Thika town in Kenya. The fruits were sun dried for ten days then decorticated manually to remove the outer shell after which the seeds were further dried for two days. Oil was extracted from the dry seeds using a mechanical pressing machine. The oil was filtered using filter bags to remove solid impurities then stored in clean, dry air-tight containers. The analytical grade reagents used were supplied by Kobian Scientific (K) Limited.

\subsection{Determination of saponification and acid value of croton oil and biodiesel}

The saponification value of croton oil was determined using the method described by Vogel, (1989) while the acid value of both the oil and biodiesel was determined using a method published by the American Oil Chemists Society (AOCS), (1980).

\subsection{Optimization of reaction parameters for biodiesel preparation}

Due to high free fatty acid content of croton oil, the biodiesel was prepared through a two stage process, which involved acid catalyzed esterification of free fatty acids followed by base catalyzed transesterification of triglycerides. The process was employed to prevent soap and emulsion formation which causes difficulties in biodiesel/glycerol separation and removal (Canakci and Van Gerpen, 2001). Both 
esterification and transesterification reactions were carried out in a thermostatic biodiesel reactor equipped with a mechanical stirrer. The reactor temperature was kept constant using a heated oil bath. The oil was first heated at $60^{\circ} \mathrm{C}$ for one hour to remove traces of moisture. The reaction conditions were optimized by varying parameters such as temperature, time, quantity of catalyst and mole ratio of reagents. The parameters were varied one at a time while keeping the others constant and their effects determined in duplicates and the mean values recorded.

\subsubsection{Acid catalyzed esterification}

The effect of concentrated sulphuric acid catalyst on esterification of free fatty acid (FFA) was determined by adding different volumes of acid to a mixture of croton oil and methanol in a biodiesel reactor. The volume of methanol required to react completely with FFA in croton oil was calculated from the acid value. Since the esterification reaction is a reversible reaction, a FFA:methanol ratio of 1:3 was used to shift the equilibrium to the right and improve the yield of ester (Equation 2). Exactly $2 \mathrm{~mL}$ of $99 \%$ pure methanol was added to different portions of $100 \mathrm{~g}$ of croton oil in a reactor and mixed for 5 minutes by stirring at $350 \mathrm{rpm}$. A graduated pipette was used to add different volumes of $98 \%$ concentrated sulfuric to each mixture. The mixture was continuously stirred while maintaining the temperature constant. The acid value of the organic layer was tested after regular intervals of time in duplicates and the mean values recorded. Similarly, the effect of temperature on the rate of esterification was determined using an acid volume of $0.4 \mathrm{~mL}$ at $40^{\circ} \mathrm{C}, 50^{\circ} \mathrm{C}$ and $60^{\circ} \mathrm{C}$.

\subsubsection{Base catalyzed transesterification}

The effect of base catalyst, Potassium hydroxide $(\mathrm{KOH})$ and volume of methanol on the rate of transesterification of croton oil was investigated by separately varying the mass of base or volume of methanol added to different portions the reaction mixture containing $100 \mathrm{~g}$ croton oil and determining their effects on the $\%$ yield of biodiesel relative to the mass of croton oil. The $\mathrm{KOH}$ was dissolved in methanol then added to the reaction mixture in a biodiesel reactor at constant temperature and stirred continuously at $350 \mathrm{rpm}$. The effects of temperature and volume of methanol on the rate of transesterification were also investigated by separately varying the temperature and volume of methanol and determining their effects on the $\%$ yield of biodiesel.

\subsubsection{Biodiesel washing and drying}

The biodiesel was repeatedly washed in a separating funnel with approximately $150 \mathrm{ml}$ portions of warm water $\left(45^{\circ} \mathrm{C}\right)$ to remove traces of alkali, soap and glycerin until clear water separated out. After each washing, the layers were allowed to settle for between 30 minutes to one hour after which the lower layer was drained out. The volume of biodiesel was accurately measured and the mean $\%$ yield recorded. The biodiesel was transferred into a clean bottle where it was dried with fused silica gel for 24 hours. The dry biodiesel was finally filtered into dry plastic containers with air-tight lids.

\subsection{Properties of croton oil and biodiesel}

The properties of croton oil and biodiesel were determined using standard methods and apparatus. The values obtained were compared with both the recommended American Society for Testing and Materials (ASTM) values and those of petro-diesel. The equipment used for determination of the pysico-chemical properties included Pensky Martins Flash Point Cup Apparatus (DM 93), density meter (DM 300), Pour and Cloud point apparatus, Fungilab viscometer (V300003) connected to thermostatic water bath and Bomb calorimeter.

\subsection{Oil extraction and properties of croton oil and biodiesel}

\section{Results and discussions}

The mechanical oil extraction produced 17 litres of croton oil from $48 \mathrm{~kg}$ of dry seeds which represented a yield of $35.42 \%(\mathrm{v} / \mathrm{w})$. The density, kinematic viscosity and acid value for croton oil of 0.9262 $\mathrm{g} / \mathrm{cm}^{3}, 30.54 \mathrm{cs}$ and $7.518 \mathrm{mg} \mathrm{KOH} / \mathrm{g}$ respectively were much higher than the recommended ASTM standards for biodiesel hence making the SVO unsuitable for direct use as a biodiesel. However, after transesterification, large transformations were observed in the corresponding values of the biodiesel which were within the range of recommended ASTM values and comparable to those of petro-diesel.The two stage process resulted in a high biodiesel yield of $88 \%(\mathrm{v} / \mathrm{v})$ with an acid value of $0.336 \mathrm{mg} \mathrm{KOH} / \mathrm{g}$. Table 1 shows the properties of croton biodiesel and the recommended ASTM values. 
Table 1: Physical Properties of Croton biodiesel

\begin{tabular}{llll}
\hline Property & Biodiesel & Petro-diesel & ASTM recommnded value \\
\hline Density $\left(40^{\circ} \mathrm{C}, \mathrm{g} / \mathrm{cm}^{3}\right)$ & 0.8858 & 0.8231 & N/A \\
Kinematic Viscosity $\left(40^{\circ} \mathrm{C}, \mathrm{cs}\right)$ & 4.51 & 2.87 & $1.9-6.0$ \\
Calorific Value $(\mathrm{j} / \mathrm{g})$ & 39179 & 44648 & Report \\
Cloud point $\left({ }^{0} \mathrm{C}\right)$ & -1.5 & 4.0 & Report \\
Pour point $\left({ }^{0} \mathrm{C}\right)$ & -6.5 & -2.0 & Report \\
Flash point $\left({ }^{0} \mathrm{C}\right)$ & $>200$ & 65 & 130 (Minimum) \\
Acid number $(\mathrm{mg} \mathrm{KOH} / \mathrm{g})$ & 0.336 & $\mathrm{ND}$ & 0.8 (maximum) \\
\hline
\end{tabular}

Both the cloud and pour point of croton biodiesel were lower than that of petro-diesel. This property showed that the biodiesel and its blends were more suitable for low temperature operations than petro-diesel. The large differences between the properties of croton oil and biodiesel were due to conversion of large and branched triglyceride molecules into lighter straight chain methyl ester (biodiesel) molecules. The results from physico-chemical properties showed that the two stage process of esterification and transesterification greatly improved the fuel properties of croton oil with respect to acid value, density and viscosity.

\subsection{Effect of temperature and acid catalyst volume on esterification}

The acid value of the organic layer decreased with increase in reaction time. The lowest acid value of $0.3 \mathrm{mg} \mathrm{KOH} / \mathrm{g}$ was attained after two hours at both $50^{\circ} \mathrm{C}$ and $60^{\circ} \mathrm{C}$ reaction temperatures and acid volumes of $0.4,0.5$ and $0.6 \mathrm{~mL}$. A more drastic initial decrease in acid value of the organic layer was observed with increase in both reaction temperature and volume of acid catalyst added to the reaction mixture. These observations could be attributed to improved reaction rate at higher temperatures and shifting of the equilibrium of the reaction represented by the general Equation 2 to the right with increased acid catalyst concentration.

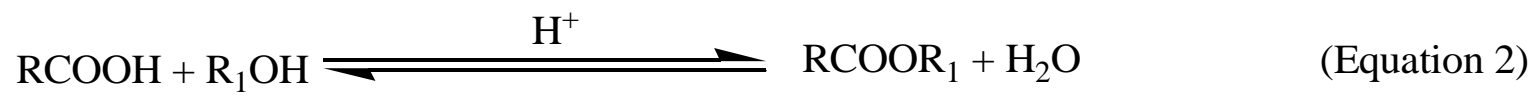

Figure 1(a) shows the variation of acid value of the organic layer with temperature while Figure 1(b) shows the effect of volume of concentrated sulphuric acid catalyst on acid value of organic layer at regular intervals of time at $50^{\circ} \mathrm{C}$.

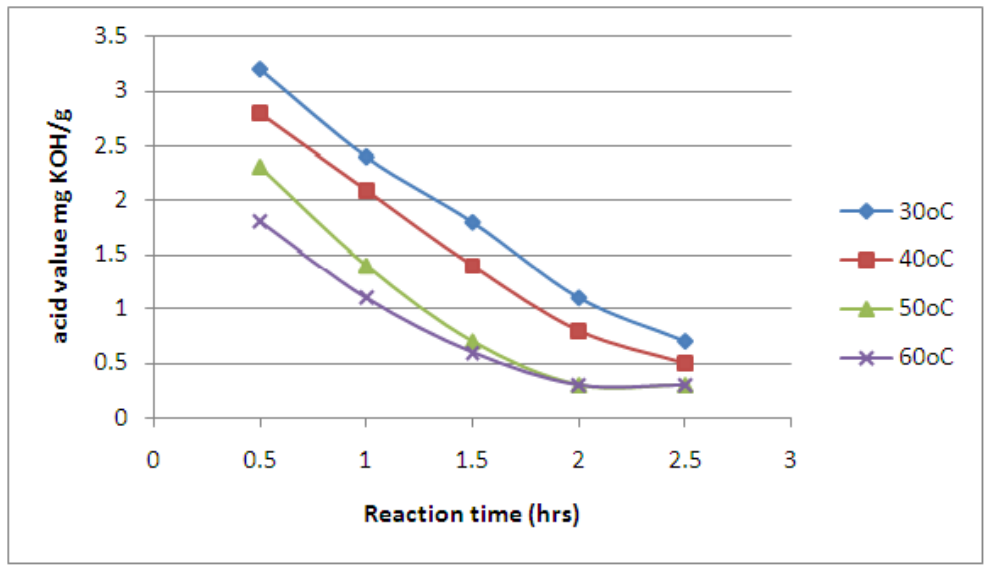

Figure 1(a): Effect of temperature on esterification

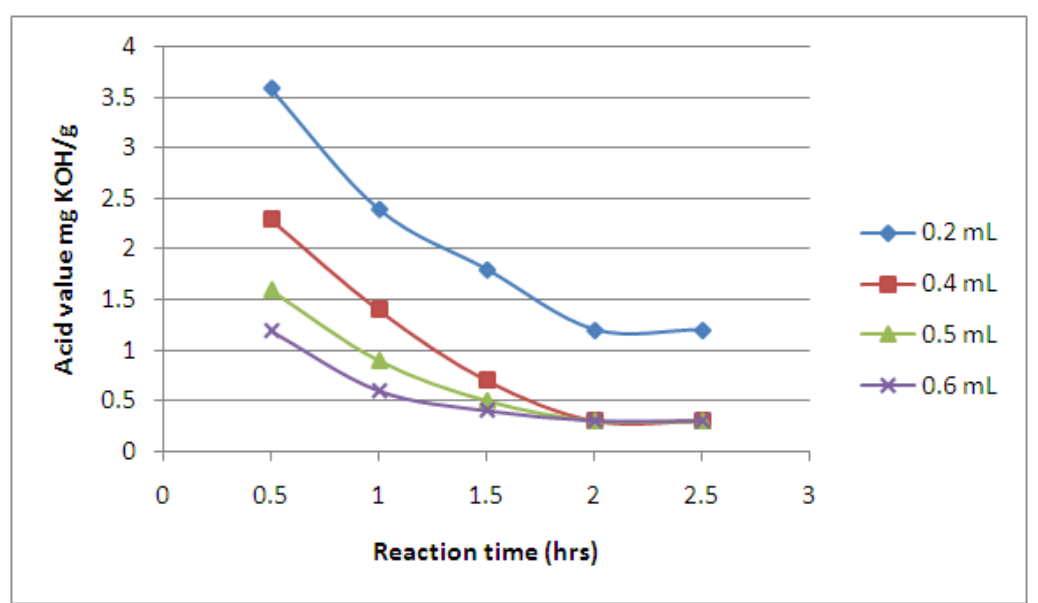

Figure 1(b): Effect of volume of acid catalyst on acid value of croton oil 


\subsection{Effect of mass of base catalyst on transesterification}

The $\%$ yield of biodiesel initially increased with increase in mass of base catalyst until a maximum yield was obtained at a base concentration of $1 \mathrm{~g}(1 \% \mathrm{w} / \mathrm{w}$ of croton oil). Further increase in mass of base catalyst added to the reaction mixture led to a decrease in $\%$ yield of biodiesel. An increase in formation of emulsion was observed at lower catalyst concentration which necessitated the need for extra washing. At higher concentrations $(>1.0 \%)$, both soap and emulsion formation occurred and a lower yield of biodiesel was obtained. Figure 2 shows the effect of mass of $\mathrm{KOH}$ added on the \% yield of biodiesel.

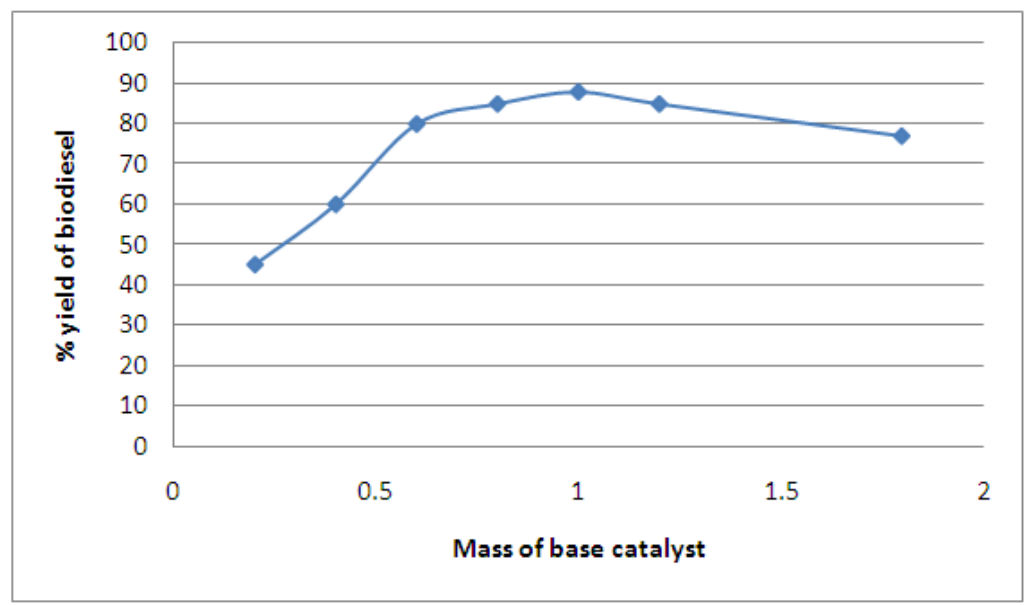

Figure 2: Effect of mass of base catalyst on yield of biodiesel

\subsection{Effect of methanol volume on biodiesel yield}

The $\%$ yield of biodiesel obtained during transesterification increased with increase in volume of methanol. The highest yield was obtained at methanol volume of $22 \mathrm{~mL}$, which corresponded to an oil:methanol molar ratio of approximately 1:6. Further increase in volume of methanol added to the reaction mixture led to decrease in \% yield of biodiesel. At lower methanol volume, increased emulsion formation was observed while higher methanol volume resulted in increased soap formation. Figure 3 shows the variation of mean $\%$ yield of croton biodiesel with volume of methanol used for transesterification.

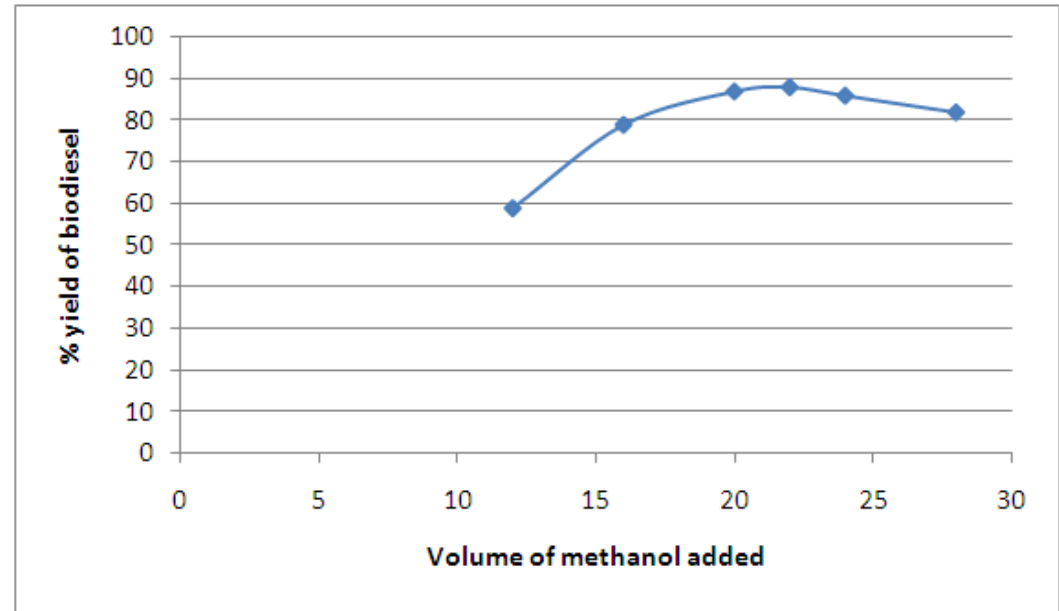

Figure 3: Effect of methanol volume on \% yield of biodiesel

\subsection{Effect of temperature and time on esterification}

The $\%$ yield of biodiesel increased with increase in reaction temperature. The maximum yield of biodiesel was obtained after one hour at a reaction temperature of $60^{\circ} \mathrm{C}$. Although the maximum yield of biodiesel increased with increase reaction time at $30^{\circ} \mathrm{C}, 40^{\circ} \mathrm{C}$ and $50^{\circ} \mathrm{C}$, no significant increase in maximum yield of biodiesel was observed at the reaction temperature of $60^{\circ} \mathrm{C}$ after one hour. Figure 4 shows the variation of yield of croton biodiesel with time at various reaction temperatures. 


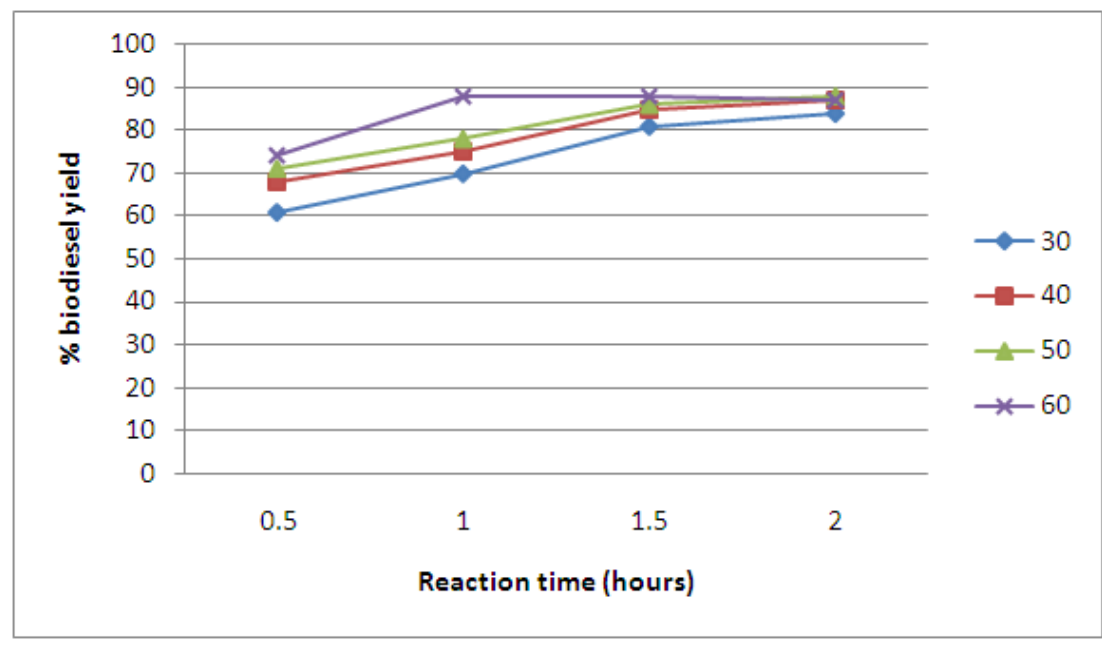

Figure 4: Effect of temperature and reaction time on the yield of Croton biodiesel

\section{Conclusions}

The two stage process of esterification of free fatty acids followed by transesterification of triglycerides resulted in a high yield of $88 \%(\mathrm{v} / \mathrm{v})$ biodiesel at optimum conditions. In addition to the higher yield at optimum reaction conditions, the biodiesel obtained separated readily from the glycerol layer and required little washing due to minimal soap and emulsion formation. However, at non-optimal conditions, a lower yield of biodiesel and increased formation of soap and emulsion which required extra washing was obtained.

The two stage biodiesel preparation process greatly improved the fuel properties of croton oil in terms of acid value, density and viscosity. The pour and cloud points of the biodiesel were lower than those of petrodiesel hence making the biodiesel and its blends more suitable for low temperature operations. The acid value of $0.336 \mathrm{mg} \mathrm{KOH} / \mathrm{g}$ for the biodiesel was much lower than the recommended ASTM value of $0.8 \mathrm{mg} \mathrm{KOH} / \mathrm{g}$ implying that the biodiesel had minimal corrosive properties on the engine. Other physico-chemical properties of croton biodiesel such as flash point were also within recommended ASTM levels.

\section{Acknowledgement}

The authors wish to express their special thanks to the National Council of Science, Technology and Innovation (NACOSTI), Kenya for the award of a grant fellowship for the procurement of reagents and certain equipment for this study.

\section{References}

[1]. Agarwal, A. K., Das, L. M. Biodiesel development and characterization for use as a fuel in compression ignition engines. ASME, Gas Turbines Power. 123, 2000, 440-447.

[2]. American Oil Chemists Society. Determination of acid value of oils. 1980

[3]. Bolza, E., and Keating, W.G. (1972). African timbers-the properties, use and characteristics of 700 species. CSIRO. Div. of Build. Res., Melbourne, Australia. 132 - 141.

[4]. Canakci, M., and Van Gerpen, J. Biodiesel Production from Oils and Fats with High Free Fatty Acids. Transactions of the American Society of Agricultural Engineers, 44(6), 2001, 1429-1436.

[5]. Christie, W. W. (1989). Gas chromatography and lipids: a practical guide, Dundee. The oily press. 36-45

[6]. Dermibas, A. Progress and recent trends in biodiesel fuels. Energy Conversion and management. Elsevier: 50, $2009,14-31$.

[7]. Robert E. B. Renewable oil fuels and diesel engines as components of sustainable system design, MSc thesis, University of Waterloo, Depatment of Science, Technology and Environment Division, 2001, 5 - 10.

[8]. Sahoo, P. K., and Das, L. M. Process optimization for biodiesel production from Jatropha, Karanja and Polanga oils. Fuel. 88, 2009, 1588 - 1594. Elsevier.

[9]. Sharma, Y. C., Singh, B., and Upadhyay, S. N. Advancement in development and characterization of biodiesel: a review. Fuel: $87(12), 2008,2355-2377$.

[10]. Sinha, A. K., Agarwal, and Garg, S. Biodiesel development from rice and bran oil: transesterification process optimization and fuel characterization. Energy Conversion and Management: 49(5), 2008, 1248 - 1257.

[11]. Taher H, Al-Zuhair S, Al-Marzouqi H. A, Haik Y. and Farid M. M. A review of enzymatic transesterification of microalgal oil based bioldiesel using supercritical technology. Enzyme Research. Hindawi Publishing Corporation: 468292, $2011,1-18$

[12]. Upadhyay, Y. P., and Sharma, R. B. Biodiesel: An alternative fuel and its emission effect. IOSR Journal of Mechanical and Civil Engineering (IOSR-JMCE): 2278-1684 Volume 5, Issue 3, 2013, 1 - 4.

[13]. Van Gerpen, J., Shanks, B., Pruszko R., Clements, D., and Knothe, G. "Biodiesel Production Technology", Report from Iowa State University for the National Renewable Energy Laboratory, NREL/SR-510-36244, 2004, 1-18.

[14]. Van Gerpen, J., Shanks, B., and Pruszko R. (2004). Biodiesel Analytical Methods. Iowa State University. National Renewable Energy Laboratory: NREL/SR-510-36240, 2004, 1-24.

[15]. Vogel, A. I. (1989). Vogel's Textbook of quantitative chemical analysis. Longman group, UK, 235 -247. 